\title{
Osthole ameliorates acute myocardial infarction in rats by decreasing the expression of inflammatory-related cytokines, diminishing MMP-2 expression and activating p-ERK
}

\author{
JUAN DUAN $^{1}$, YU YANG ${ }^{1}$, HONG LIU $^{1}$, PENG-CHENG DOU ${ }^{2}$ and SHENG-YU TAN ${ }^{1}$ \\ Departments of ${ }^{1}$ Geriatrics and ${ }^{2}$ Orthopedics, The Second Xiangya Hospital \\ of Central South University, Changsha, Hunan 410011, P.R. China
}

Received May 15, 2015; Accepted October 23, 2015

DOI: $10.3892 / \mathrm{ijmm} .2015 .2402$

\begin{abstract}
Osthole, the active constituent of Cnidium monnieri extracts, has been shown to have a diverse range of pharmacological properties. In the present study, we aimed to evaluate the cardioprotective effects of osthole in a rat model of acute myocardial infarction (AMI). The rats with AMI were treated with 1,3 and $10 \mathrm{mg} / \mathrm{kg}$ of osthole or the vehicle for 4 weeks. The infarct size of the rats with AMI was measured, and casein kinase $(\mathrm{CK})$, the $\mathrm{MB}$ isoenzyme of creatine kinase (CK-MB), lactate dehydrogenase (LDH) and cardiac troponin $\mathrm{T}$ (cTnT) activities in the rats with AMI were analyzed using commercially available kits. The nuclear factor- $\kappa \mathrm{B}(\mathrm{NF}-\kappa \mathrm{B})$, tumor necrosis factor- $\alpha$ (TNF- $\alpha$ ), interleukin (IL)- $1 \beta$ and IL-6 levels in whole blood from rats with AMI were also detected using commercially available kits. The levels of Toll-like receptors 2/4 (TLR2/4) and nucleotide-binding oligomerization domain-containing protein 1/2 (NOD1/2) were also detected by RT-qPCR. Moreover, the protein expression levels of endothelial nitric oxide synthase (eNOS) and mitogen-activated protein kinase (MAPK) cascades, including extracellular signal-regulated kinase (ERK), c-Jun N-terminal kinase (JNK) and p38, cyclooxygenase-2 (COX-2), as well as matrix metalloproteinase-2 (MMP-2) were all assayed by western blot analysis. Our results revealed that osthole markedly reduced the infarct size, and the levels of CK, CK-MB, LDH and cTnT in the rats with AMI, and that these cardioprotective effects may be associated with the inhibition of inflammatory reactions, the reduction in MMP-2 activity and the activation of MAPK cascades.
\end{abstract}

Correspondence to: Dr Sheng-Yu Tan, Department of Geriatrics, The Second Xiangya Hospital of Central South University, 139 Renmin Road, Changsha, Hunan 410011, P.R. China

E-mail: sytdr2015@163.com

Key words: osthole, acute myocardial infarction, inflammatory, endothelial nitric oxide synthase, mitogen-activated protein kinases, matrix metalloproteinase- 2

\section{Introduction}

Acute myocardial infarction (AMI) results in myocardial necrosis and is caused by acute coronary artery disease and persistent ischemia and hypoxia. There have been many documented clinical cases of severe and persistent pain behind the sternum, which cannot be completely relieved by rest and nitrate esters. AMI is associated with an increase in serum myocardial enzyme activity and progressive changes in the electrocardiogram, and can cause arrhythmia, heart failure or shock and is often fatal (1). This disease is common in Europe and America, and appoximately 620,000 Americans suffer from heart disease in the US each year (2).

During the development of AMI, the inflammatory reaction plays a key role in all types of damage factors, and it can be viewed as the intermediary link between the generation and development of various injury factors and damage to cardiac muscle. Under normal circumstances, inflammatory cells and vascular endothelial cells do not attach, or hardly attach; however, following stimulation with inflammatory factors, adhesion molecules are rapidly activated and help inflammatory cells to attach and accumulate in endothelial cells; this is followed by the release of inflammatory mediators and damage to endothelial cells (3).

Matrix metalloproteinases (MMPs) are a family of enzymes that contain at least 26 members. Previous research has indicated that MMPs can adjust and control the synthesis and degradation of the extracellular matrix (ECM), and they are the main factor contributing to plaque rupture and can thus participate in ventricular reconstruction (4). MMP-2 and MMP-9 are the most important members of MMPs, and both are secreted by vascular smooth muscle cells. The expression of these two MMPs is significantly increased in patients with atherosclerotic plaque, which can cause specific degradation of the ECM and may also cause plaque rupture, thus leading to the development of AMI (5).

Mitogen-activated protein kinases (MAPKs) are signaling mediators that connect cell-surface receptors to intracellular critical regulatory targets. There is emerging evidence indicating that the MAPK cascades regulate a variety of cellular activities, such as cell growth, survival and death (6). The MAPK family includes at least three distinct subgroups, namely extracellular 
signal-regulated kinase (ERK), c-Jun N-terminal kinase (JNK)/ stress-activated protein kinase (SAPK, and p38 in mammalian cells (7). A previous study demonstrated the transient activation of ERK in cultured rat neonatal cardiac myocytes following exposure to hydrogen peroxide; the inhibition of the activation of ERK exacerbated cardiomyocyte apoptosis (8). Moreover, it has been demonstrated that the JNK pathway is specifically activated following the transfection of cultured neonatal rat cardiac myocytes with recombinant adenoviral vectors expressing a constitutively active mutant of MKK7 (or JNKK2), an upstream activator of JNK, which contributed to the induction of hypertrophic responses (9). As regards the role of the p38 signaling pathway in cardiomyocyte apoptosis, a previous study demonstrated that $\mathrm{p} 38$ was activated in neonatal rat cardiomyocytes due to ischemia and that the inhibition of $\mathrm{p} 38$ protected cardiac myocytes from apoptosis (10).

It has also been previously reported that osthole, the active constituent of Cnidium monnieri extracts, has anti-inflammatory and hepatic fat-oxidizing properties (11). Osthole has been shown to effectively inhibit the activation of the MMP-2 promoter and its enzyme, which may be one of the mechanisms involed in cellular migration and invasion (12). The present study is the first, to the best of our knowledge, which investigated the hypothesis that osthole decreases the expression of Toll-like receptor (TLR)2 and TLR4, nucleotide-binding oligomerization domaincontaining protein (NOD)1, NOD2, increases endothelial nitric oxide synthase (eNOS) and decreases cyclooxygenase-2 (COX-2) expression in a rat model of AMI. We wished to examine whether these effects are mediated through the inhibition of inflammatory reactions, a decrease in MMP-2 expression and the activation of MAPK cascades.

\section{Materials and methods}

Drugs, reagents and kits. The chemical structure of osthole is depicted in Fig. 1. Osthole (with a purity of 95\%; Sigma-Aldrich Co., St. Louis, MO, USA), was dissolved in physiological saline. Casein kinase (CK), the MB isoenzyme of creatine kinase (CK-MB), lactate dehydrogenase (LDH) and cardiac troponin $\mathrm{T}$ (cTnT) commercial kits were purchased from Sangon Biotech (Shanghai, China). Nuclear factor- $\mathrm{B}(\mathrm{NF}-\kappa \mathrm{B})$, tumor necrosis factor- $\alpha$ (TNF- $\alpha$ ), interleukin (IL)-1 $\beta$ and IL-6 commercial kits were purchased from Jiancheng Bioengineering (Nanjing, China). A BCA protein assay kit was purchased from Tiangen (Beijing, China). Caspase- 3 and caspase-9 activity assay kits were purchased from Sangon Biotech.

Experimental animals. A total of 50 healthy male Wistar rats (weighing 220-250 g) were obtained from the Experimental Animal Center of the Second Xiangya Hospital of Central South University (Changsha, China). All experimental procedures were approved by the Second Xiangya Hospital of Central South University and were performed in accordance with the ethical standards of our institution. All experimental rats were allowed to acclimatize in enriched plastic cages and had free access to food and clean drinking water.

Induction of AMI and group design. The rats were operated on after being intraperitoneally anesthetized using sodium pentobarbitone $(40 \mathrm{mg} / \mathrm{kg})$. The model of AMI was created by ligating the left anterior descending coronary artery, as previously described (13). The successful establishment of the rat model of AMI was confirmed by the presence of regional cyanosis on the myocardial surface and represented by the elevation of the ST-segment. All experimental rats were randomly divided into 5 groups as follows ( $\mathrm{n}=10$ in each group): i) the sham-operated group; ii) the vehicle-treated group; iii) the group treated with $1 \mathrm{mg} / \mathrm{kg}$ osthole; iv) the group treated with $3 \mathrm{mg} / \mathrm{kg}$ osthole and v) the group treated with $10 \mathrm{mg} / \mathrm{kg}$ osthole. The rats in the osthole-treated groups were treated with various doses of osthole $(1,3$ and $10 \mathrm{mg} / \mathrm{kg})$ once a day for 4 weeks. The dosage and dosage frequency were determined on the basis of the findings of a previous study (14). Rats in the sham-operated group were not operated upon. Rats in the vehicle-treated group underwent the procedure of AMI after being injected with the same volume of physiological saline. Rats in the osthole-treated group underwent the procedure of AMI after being injected with osthole though the tail veil. The rats were treated with physiological saline or osthole once a day for 4 weeks. The rats were operated on (occlusion of the coronary artery) $30 \mathrm{~min}$ after the final injection. The coronary artery was occluded with a 1-2 mm of 5-0 silk suture for encircling the left anterior descending coronary artery below the left atrial appendage.

Measurement of infarct size. The hearts of the experimental rats were immediately measured through the aorta and washed with physiological saline. The coronary artery was occluded and after $6 \mathrm{~h}$, the left ventricle was placed in a freezer at $-80^{\circ} \mathrm{C}$ for 5-10 min. Subsequently, it was sliced into $2-\mathrm{mm}$-thick sections in order to measure the infarct size. The infarct size of the rats was measured using 1\% 2,3,5-triphenyltetrazolium chloride (1.5\%; Sigma-Aldrich Co.) at $37^{\circ} \mathrm{C}$ for $30 \mathrm{~min}$ in the dark $(15,16)$. The area of the heart without color was regarded as the ischemic heart muscle, and the area which was colored brick red was regarded as the normal myocardium. The size of the infarct area was measured by calculating the volume and weight as a percentage of the left ventricle.

Measurementoflevels of plasma cardiac marker enzymes. Serum samples of rats were extracted from the vena cava following the occlusion of the coronary artery for $6 \mathrm{~h}$. Serum samples were then centrifuged at $1,000 \mathrm{xg}$ for $25 \mathrm{~min}$ and were saved for measurement at $-20^{\circ} \mathrm{C}$. The CK, CK-MB, $\mathrm{LDH}$ and cTnT activities in the rats were analyzed using a series of commercial kits (Sangon Biotech) according to the manufacturer's instructions.

$R N A$ extraction and reverse transcription-quantitative PCR $(R T-q P C R)$. The heart samples were collected, and total RNA was extracted and purified using TRIzol reagent following the manufacturer's instructions (Invitrogen, Carlsbad, CA, USA). Subsequently, $1 \mu \mathrm{g}$ of total RNA from the heart samples was used to perform first-strand cDNA synthesis and this first-strand cDNA was transcribed into cDNA using random hexamers (Promega, Beijing, China) according to the manufacturer's instructions. The StepOnePlus real-time PCR system was used to perform quantitative (real-time) PCR (qPCR) using power SYBR-Green PCR Master Mix (Applied Biosystems, Foster, CA, USA). Ten microliters of power SYBR-Green PCR master mix, $1 \mu 1$ of cDNA, $2 \mu 1$ of primers and $7 \mu 1$ of PCR-grade water were blended and PCR was then performed. The reactions were 


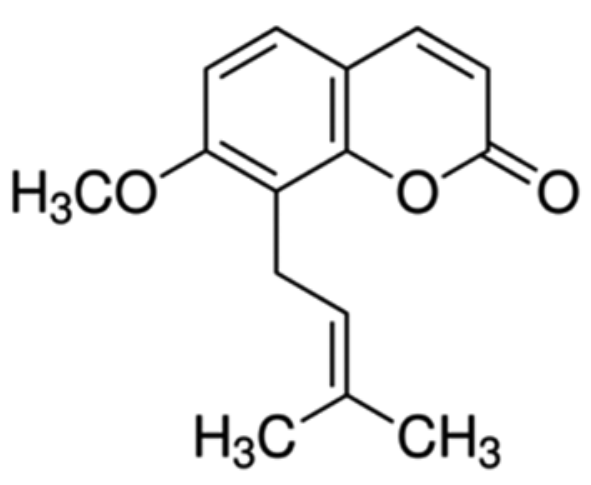

Figure 1. Chemical structure of osthole.

performed at $95^{\circ} \mathrm{C}$ for $10 \mathrm{~min}$, followed by 35 cycles of $95^{\circ} \mathrm{C}$ for $30 \mathrm{sec}, 58^{\circ} \mathrm{C}$ for $45 \mathrm{sec}$, and $72^{\circ} \mathrm{C} 30 \mathrm{sec}, 4^{\circ} \mathrm{C}$ for saving. The sequences for the gene-specific primers are listed in Table I.

Western blot analysis. The heart samples were lysed in ice-cold RIPA buffer (Beyotine Biotechnology, Natong, China) containing $10 \mathrm{mM}$ Tris ( $\mathrm{pH} 8.0$ ), $150 \mathrm{mM} \mathrm{NaCl}, 10 \%$ glycerol, $1 \%$ NP-40, 5 mM EDTA and protease inhibitor cocktail. An equal amount of protein $(60 \mu \mathrm{g})$ was separated by electrophoresis on 8 or $10 \%$ sodium dodecyl sulfate (SDS)-polyacrylamide (SDS-PAGE) gels and transferred onto nitrocellulose membranes (Millipore, Billerica, MA, USA). After blocking in $5 \%$ fat-free milk, the membranes were incubated with the following primary antibodies: rabbit anti-eNOS (1:300; sc-49055), rabbit anti-COX-2 (1:500; sc-7951), mouse antiphosphorylated (p-)JNK (Thr183/Tyr185) (1:200; sc-293136), rabbit anti-p-p38 MAPK (Tyr182) (1:200; sc-101758), mouse anti-p-ERK (Tyr204) (1:200; sc-377400) (all from Santa Cruz Biotechnology, Inc., Santa Cruz, CA, USA) and mouse anti- $\beta$ actin (1:2,000; KC-5A08; Kangchen, Beijing, China), overnight at $4^{\circ} \mathrm{C}$. The membranes were then treated with horseradish peroxidase-conjugated goat anti-rabbit antibody $(1: 5,000$; sc-2004) or goat anti-mouse antibody $(1: 5,000 ;$ sc-2005) (both from Santa Cruz Biotechnology, Inc.) for $2 \mathrm{~h}$. Immunodetection was carried out with an enhanced chemiluminescence (ECL) kit (Pierce, Burlingame, CA, USA).

Determination of plasma nitrite production. Nitric oxide (NO) production was determined by measuring the plasma supernatant for nitrite using Griess reagent (Promega). The absorbance was recorded at a wavelength of $540 \mathrm{~nm}$, and the nitrite concentration was determined using sodium nitrite as the standard.

Measurement of NF- $\kappa B$, tumor necrosis factor- $\alpha$ (TNF- $\alpha)$, $I L-1 \beta$ and $I L-6$ levels. Whole blood of rats was collected into a serum separator tube for $30 \mathrm{~min}$ after a 6 -h ischemic period. Serum samples were then centrifuged at $1,000 \mathrm{x}$ g for $25 \mathrm{~min}$ and were kept for the measurement at $-20^{\circ} \mathrm{C}$. A commercial ELISA kit was used to measure the serum levels of $\mathrm{NF}-\kappa \mathrm{B}$, TNF- $\alpha$, IL- $1 \beta$ and IL- 6 in rats according to the manufacturer's instructions.

Measurement of MMP-2 levels. Following treatment with osthole, MMP-9 markers were detected by gelatin zymography
Table I. Sequences of gene-specific primers used for RT-qPCR.

\begin{tabular}{|c|c|c|}
\hline Gene & $\begin{array}{l}\text { Primer sequence } \\
\qquad\left(5^{\prime} \rightarrow 3^{\prime}\right)\end{array}$ & $\begin{array}{l}\text { Product } \\
\text { size (bp) }\end{array}$ \\
\hline TLR2 & $\begin{array}{l}\text { TCTCCCATTTCCGTCTTTTT } \\
\text { GGTCTTGGTGTTCATTATCTTC }\end{array}$ & 125 \\
\hline TLR4 & $\begin{array}{l}\text { GAAGCTGGTGGCTGTGGA } \\
\text { TGATGTAGAACCCGCAAG }\end{array}$ & 213 \\
\hline NOD1 & $\begin{array}{l}\text { GTCACTGAGGTCCATCTGAAC } \\
\text { CATCCACTCCTGGAAGAACCT }\end{array}$ & 363 \\
\hline NOD2 & $\begin{array}{l}\text { CATGTGCTGCTACGTGTTCTC } \\
\text { CCTGCCACAATTGAAGAGGTG }\end{array}$ & 226 \\
\hline COX -2 & $\begin{array}{l}\text { CAAATCCTTGCTGTTCCCACCCAT } \\
\text { GTGCACTGTGTTTGGAGTGGGTTT }\end{array}$ & 173 \\
\hline$\beta$-actin & $\begin{array}{l}\text { AGCGAGCATCCCCCAAAGTT } \\
\text { GGGCACGAAGGCTCATCATT }\end{array}$ & 284 \\
\hline
\end{tabular}

TLR, Toll-like receptor; NOD, nucleotide-binding oligomerization domain-containing protein; COX-2, cyclooxygenase- 2 .

assays. A total of $50 \mu \mathrm{g}$ of samples were absorbed into a new centrifuge tube, and an equal volume of SDS sample buffer was then added to the centrifuge tube. The miscible liquids were subjected to $10 \%$ SDS-PAGE electrophoresis on a gel impregnated with $0.1 \%$ gelatin. The gel was washed 3 times for $20 \mathrm{~min}$ at room temperature in $2.5 \%$ Triton X-100 to remove the SDS after electrophoresis. The gel was incubated in reaction buffer at $37^{\circ} \mathrm{C}$ for $12 \mathrm{~h}$. Subsequently, the gel was stained with $0.05 \%$ Coomassie brilliant blue R-250.

Caspase-3 and caspase-9 activity assay. Approximately $50 \mu \mathrm{g}$ cardiac cytosolic protein was incubated in solution buffer at $37^{\circ} \mathrm{C}$ for $30 \mathrm{~min}$. Briefly, caspase -3 and caspase -9 activity was measured using a caspase- 3 and caspase- 9 activity assay kit (Sangon Biotech). A total of $10 \mu \mathrm{l}$ protein cell lysate per sample was added to $80 \mu \mathrm{l}$ reaction buffer with $10 \mu \mathrm{l}$ substrate Asp-Glu-Val-Asp (DEVD)-p-nitroaniline (pNA) and incubated at $37^{\circ} \mathrm{C}$ for $4-6 \mathrm{~h}$. Caspase-3 activation was measured using a microplate reader (Bio-Rad, Hercules, CA, USA) at an absorbance of $405 \mathrm{~nm}$. The change in fluorescence (excitation at $400 \mathrm{~nm}$ ) was detected at a wavelength of $405 \mathrm{~nm}$.

Statistical analysis. Data are expressed as the means \pm SD and were analyzed using SPSS 17.0 software. Differences between the experimental groups were analyzed using the Student's $\mathrm{t}$-test. Values of $\mathrm{p}<0.05$ were considered to indicate statistically significant differences.

\section{Results}

Effects of osthole on myocardial infarct size. The chemical structure of osthole is illustrated in Fig. 1. Firstly, we examined the effects of osthole on the myocardial infarct size in the rats with AMI. After the operation, the rats with AMI were treated with various doses $(1,3$ and $10 \mathrm{mg} / \mathrm{kg})$ of osthole for 4 weeks. 
Table II. Effects of osthole on plasma cardiac marker enzymes.

\begin{tabular}{llccc}
\hline Groups & CK $(\mathrm{U} / \mathrm{ml})$ & CK-MB (IU/l) & LDH $(\mathrm{U} / \mathrm{l})$ & cTnT (U/ml) \\
\hline Sham & $0.24 \pm 0.03$ & $79.27 \pm 6.72$ & $1836.63 \pm 292.12$ & $0.07 \pm 0.04$ \\
Vehicle & $0.58 \pm 0.05^{\mathrm{a}}$ & $189.00 \pm 9.31^{\mathrm{a}}$ & $3713.25 \pm 367.83^{\mathrm{a}}$ & $0.32 \pm 0.06^{\mathrm{a}}$ \\
$1 \mathrm{mg} / \mathrm{kg}$ & $0.41 \pm 0.04^{\mathrm{b}}$ & $111.75 \pm 7.45^{\mathrm{c}}$ & $3055.25 \pm 330.39^{\mathrm{b}}$ & $0.15 \pm 0.04^{\mathrm{c}}$ \\
$3 \mathrm{mg} / \mathrm{kg}$ & $0.31 \pm 0.04^{\mathrm{c}}$ & $94.47 \pm 10.99^{\mathrm{c}}$ & $2541.25 \pm 365.82^{\mathrm{c}}$ & $0.13 \pm 0.07^{\mathrm{c}}$ \\
$10 \mathrm{mg} / \mathrm{kg}$ & $0.24 \pm 0.03^{\mathrm{c}}$ & $83.60 \pm 8.32^{\mathrm{c}}$ & $2256.13 \pm 301.77^{\mathrm{c}}$ & $0.12 \pm 0.03^{\mathrm{c}}$ \\
\hline
\end{tabular}

${ }^{\mathrm{a}} \mathrm{p}<0.01$ vs. sham-operated (sham) group; ${ }^{\mathrm{b}} \mathrm{p}<0.05$ and ${ }^{\mathrm{c}} \mathrm{p}<0.01$ vs. vehicle-treated (vehicle) group. Rats were treated with various doses of osthole $(1,3$ and $10 \mathrm{mg} / \mathrm{kg})$. CK, casein kinase; CK-MB, MB isoenzyme of creatine kinase; LDH, lactate dehydrogenase; cTnT, cardiac troponin T.

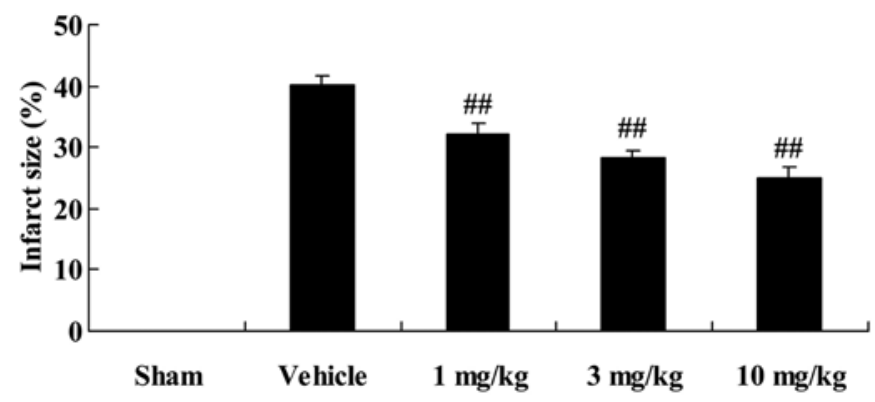

Figure 2. Effects of osthole on myocardial infarct size. ${ }^{\# \#} \mathrm{p}<0.01$ vs. vehicletreated (vehicle) group. Rats were treated with 1,3 and $10 \mathrm{mg} / \mathrm{kg}$ of osthole.

As shown in Fig. 2, treatment with 1,3 and $10 \mathrm{mg} / \mathrm{kg}$ of osthole significantly inhibited the myocardial infarct size of the rats with AMI ( $\mathrm{p}<0.01)$, compared with the vehicle-treated group (Fig. 2).

Effects of osthole on the levels of plasma cardiac marker enzymes. We examined the effects of osthole on the levels of plasma cardiac marker enzymes. CK, CK-MB, LDH and cTnT activities were measured to analyze its curative effects on AMI. CK, CK-MB, LDH and cTnT activities were higher in the vehicle-treated group compared to the sham-operated group ( $<<0.01$; Table II). However, treatment with osthole significantly inhibited the CK, CK-MB, LDH and cTnT activities in the rats with AMI in a dose-dependent manner $(\mathrm{p}<0.05$ and $\mathrm{p}<0.01)$ compared to the vehicle-treated group (Table II).

Effects of osthole on TLR2 and TLR4 gene expression. Our results revealed that treatment with osthole markedly decreased the mRNA expression levels of TLR2 and TLR4 in the rats with AMI compared to the vehicle-treated group (Fig. 3).

Effects of osthole on NOD1 and NOD2 gene expression. After 4 weeks of osthole treatment, RT-qPCR was performed to measure the mRNA expression levels of NOD1 and NOD2 in the rats with AMI. It should be noted that there was no significant difference in the mRNA expression of NOD1 between the sham-operated group and the vehicle-treated group (Fig. 4A). Following treatment of the rats with AMI with osthole at the doses of 1,3 and $10 \mathrm{mg} / \mathrm{kg}$, NOD1 mRNA expression was significantly decreased in a dose-dependent manner $(\mathrm{p}<0.01)$, compared to the vehicle-treated group (Fig. 4A). As regards NOD2 mRNA expression, a signficant increase was observed in the vehicle-treated group $(\mathrm{p}<0.01)$, in comparison with the sham-operated group, although NOD2 expression was significantly $(\mathrm{p}<0.01)$ downregulated in a dose-dependant manner following treatment with osthole (Fig. 4B). Thus, the administration of osthole at the doses of 1,3 and $10 \mathrm{mg} / \mathrm{kg}$ reversed the increase in NOD2 mRNA expression in the rats with AMI (Fig. 4B).

Effects of osthole on eNOS expression. We examined the effects of osthole on eNOS expression in the rats with AMI; eNOS protein expression and production were examined in the rats in the different groups. As depicted in Fig. 5A and B, following the induction of AMI, eNOS protein expression markedly decreased in the vehicle-treated group $(\mathrm{p}<0.01)$ in comparison with the sham-operated group. Notably, compared to the vehicle-treated group, treatment with osthole at 1,3 and $10 \mathrm{mg} / \mathrm{kg}$ significantly increased eNOS protein expression in the rats with AMI ( $<<0.01$; Fig. 5A and B). We also noted that nitrite production was higher in the sham-operated group (Fig. 5C). Moreover, following treatment with osthole (1, 3 and $10 \mathrm{mg} / \mathrm{kg}$ ), a marked increase in nitrite production was noted $(\mathrm{p}<0.01)$ compared to the vehicle-treated group.

Effects of osthole on COX-2 expression. To examine the effects of osthole on COX-2 expression in the rats with AMI, we measured the expression levels of COX-2 at the mRNA and protein level in the different groups. The results revealed that the rats with AMI exhibited an increase in COX-2 expression at both the mRNA (gene) and protein level in comparison to the sham-operated group (Fig. 6). However, treatment with osthole $(1,3$ and $10 \mathrm{mg} / \mathrm{kg})$ significantly inhibited the upregulation of COX-2 expression in the rats with AMI $(\mathrm{p}<0.01)$, compared to the vehicle-treated group.

Effects of osthole on the activities of NF- $\kappa B, T N F-\alpha, I L-1 \beta$ and IL-6. We quantified the activities of NF-KB, TNF- $\alpha$, IL- $1 \beta$ and IL-6 in the different groups of rats. As illustrated in Fig. 7, NF- $\kappa B, T N F-\alpha$, IL- $1 \beta$ and IL- 6 activities in the rats with AMI were significantly increased $(\mathrm{p}<0.01)$, in comparison wtih the sham-operated rats. However, the levels of these inflammatory factors were significantly reduced following treatment with osthole (1,3 and $10 \mathrm{mg} / \mathrm{kg}$; p <0.01; Fig. 7).

Effects of osthole on MMP-2 protein expression. In the present study, we examined the effects of osthole oin the inflamma- 

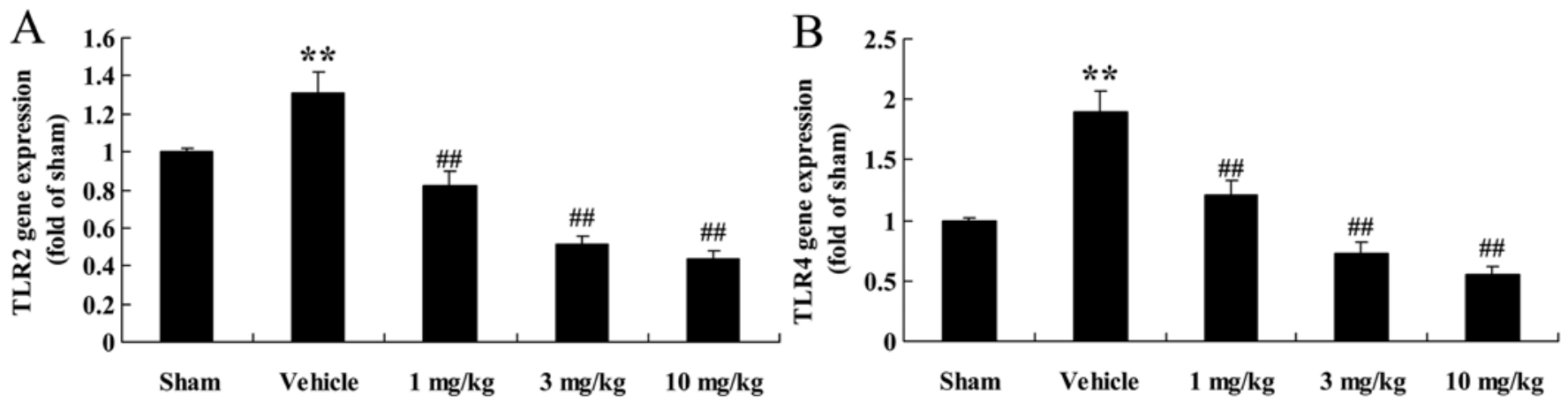

Figure 3. Effects of osthole on Toll-like receptor (TLR) gene expression. (A) TLR2 and TLR4 (B). ${ }^{* *} \mathrm{p}<0.01$ vs. sham-operated (sham) group; ${ }^{\# \#} \mathrm{p}<0.01 \mathrm{vs.} \mathrm{vehicle-}$ treated (vehicle) group. Rats were treated with 1,3 and $10 \mathrm{mg} / \mathrm{kg}$ of osthole.
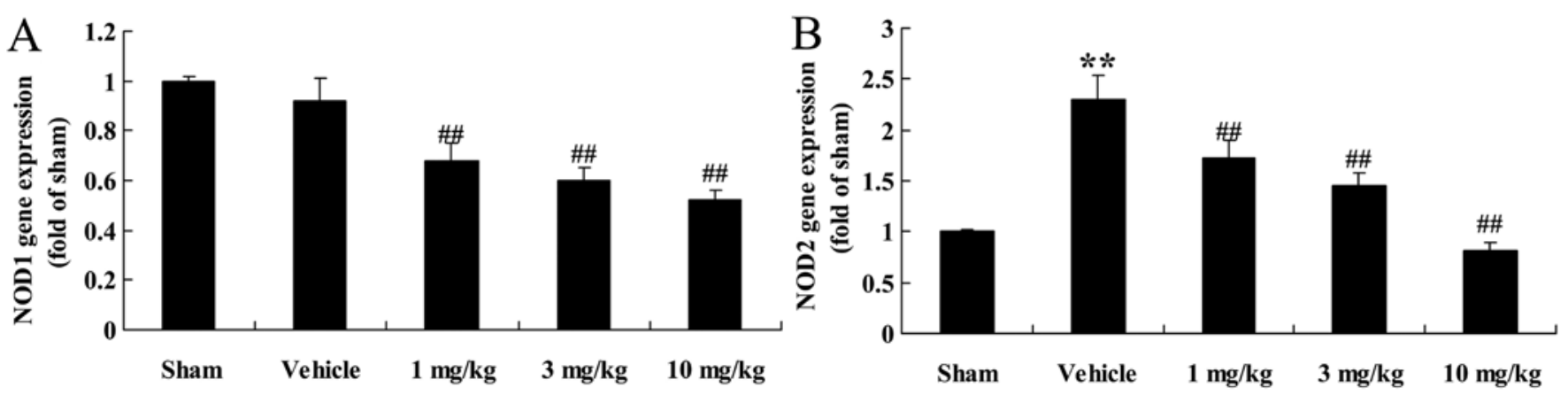

Figure 4. Effects of (A) osthole on binding oligomerization domain (NOD)1 and (B) NOD2 gene expression. ${ }^{* *} \mathrm{p}<0.01$ vs. sham-operated (sham) group; ${ }^{\sharp \#} \mathrm{p}<0.01$ vs. vehicle-treated (vehicle) group. Rats were treated with 1,3 and $10 \mathrm{mg} / \mathrm{kg}$ of osthole.

\section{A}

\section{eNOS}

$\beta$-actin

Sham Vehicle $1 \mathrm{mg} / \mathrm{kg} 3 \mathrm{mg} / \mathrm{kg} 10 \mathrm{mg} / \mathrm{kg}$
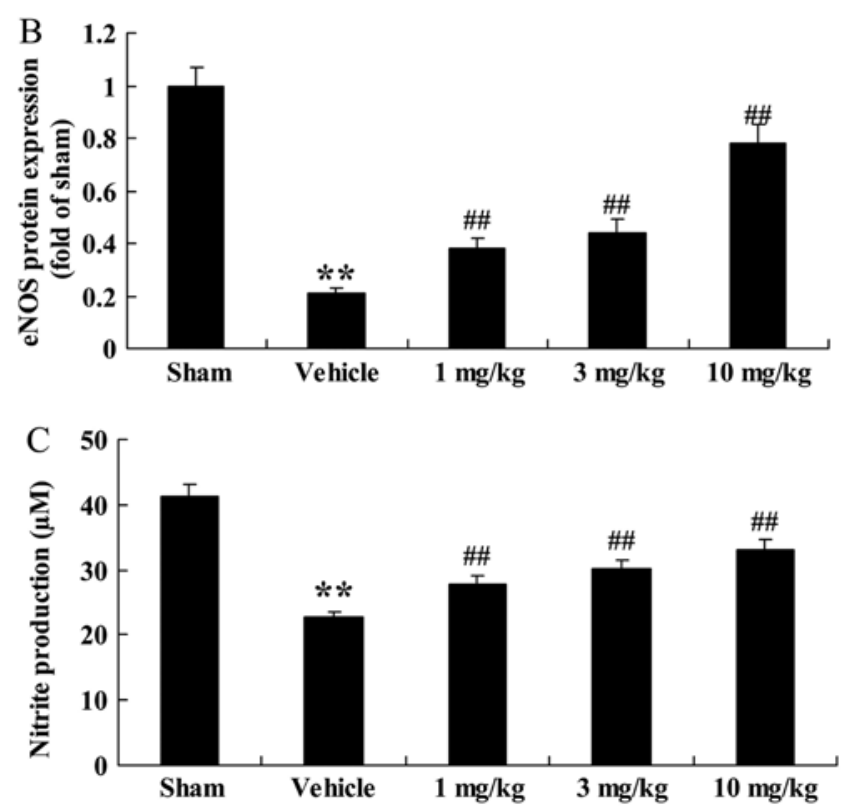

Figure 5. Effects of osthole on endothelial nitric oxide synthase (eNOS) protein expression levels (A) using western blot analysis, (B) statistical analysis of eNOS protein expression levels, and (C) plasma nitrite production. ${ }^{* *} \mathrm{p}<0.01$ vs. sham-operated (sham) group; ${ }^{\# \#} \mathrm{p}<0.01$ vs. vehicle-treated (vehicle) group. Rats were treated with 1,3 and $10 \mathrm{mg} / \mathrm{kg}$ of osthole.

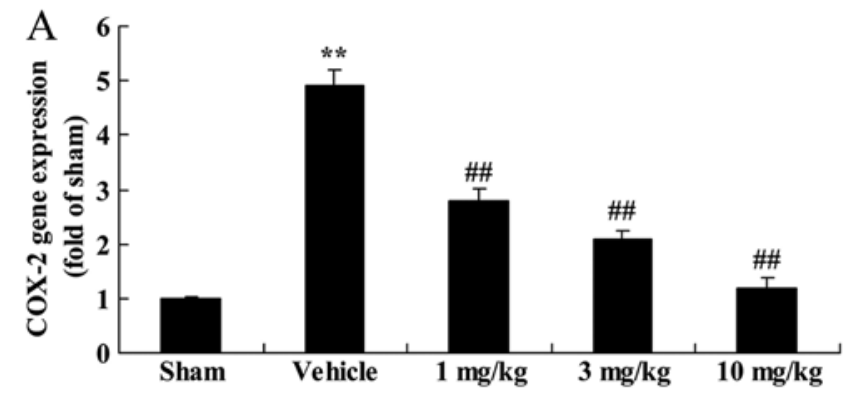

B
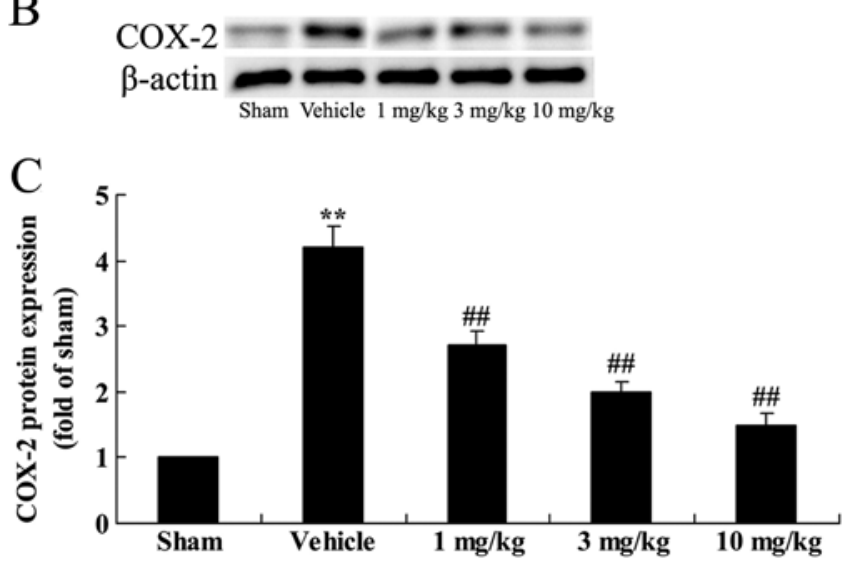

Figure 6. Effects of osthole on the (A) gene and (B and C) protein expression of cyclooxygenase-2 (COX-2). ${ }^{* *} \mathrm{p}<0.01$ vs. sham-operated (sham) group; ${ }^{\# \#} \mathrm{p}<0.01$ vs. vehicle-treated (vehicle) group. Rats were treated with 1,3 and 10 $\mathrm{mg} / \mathrm{kg}$ of osthole. 

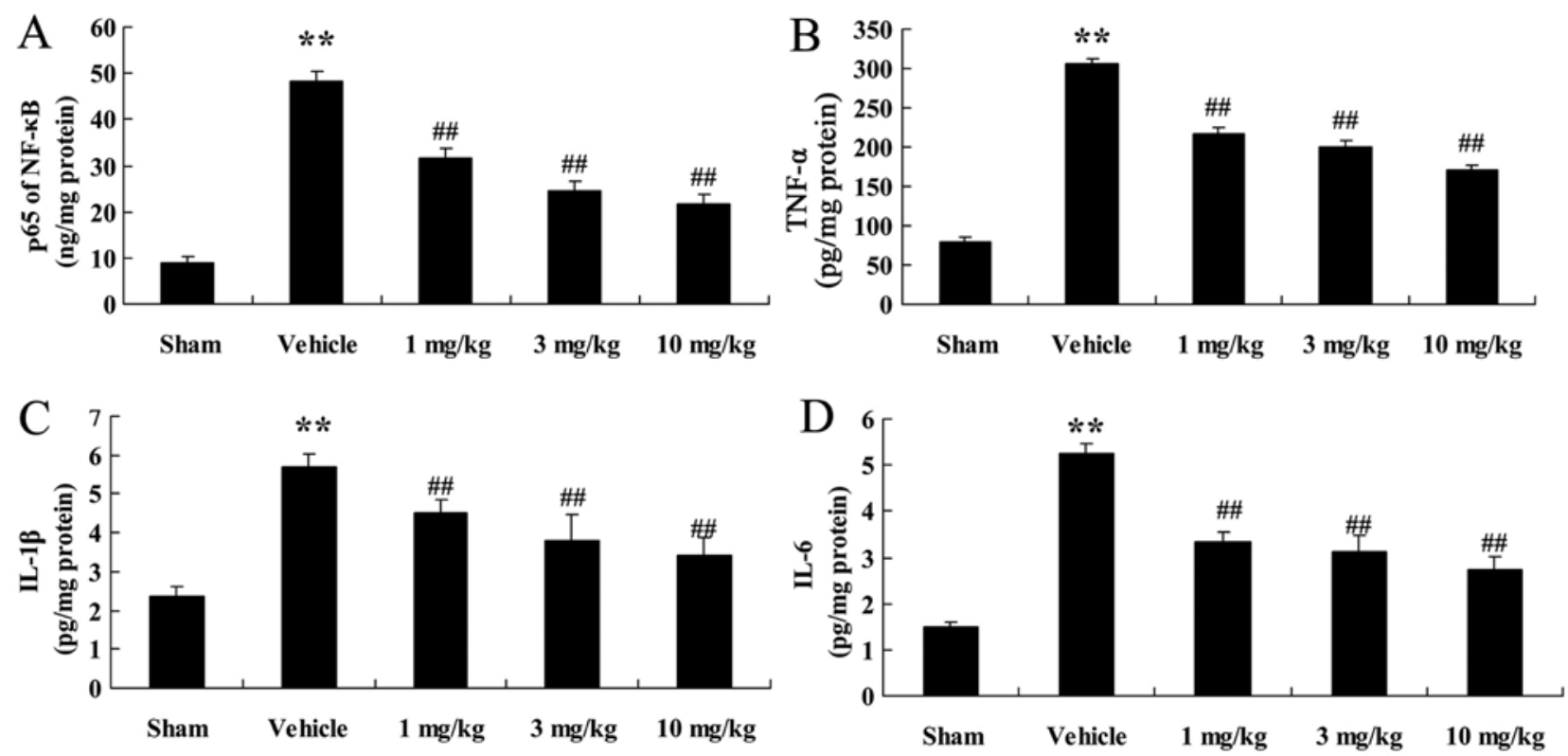

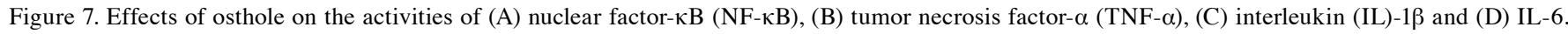
${ }^{* *} \mathrm{p}<0.01$ vs. sham-operated (sham) group; ${ }^{\# /} \mathrm{p}<0.01 \mathrm{vs}$. vehicle-treated (vehicle) group. Rats were treated with 1,3 and $10 \mathrm{mg} / \mathrm{kg}$ of osthole.
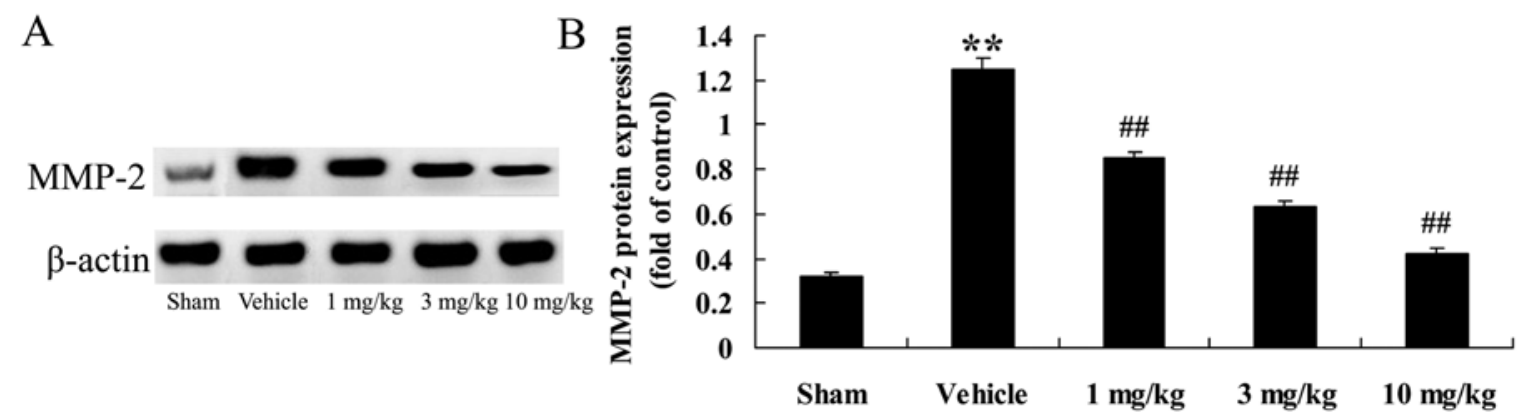

Figure 8. Effects of osthole on matrix metalloproteinase-2 (MMP-2) protein expression levels (A) using western blot analysis and (B) statistical analysis of MMP-2 protein expression levels. ${ }^{* *} \mathrm{p}<0.01$ vs. sham-operated (sham) group; ${ }^{\# \#} \mathrm{p}<0.01$ vs. vehicle-treated (vehicle) group. Rats were treated with 1,3 and $10 \mathrm{mg} /$ $\mathrm{kg}$ of osthole.

tory reaction. We measured MMP-2 protein expression in the different groups of rats. Compared to the sham-operated group, the rats with AMI (vehicle-treated group) exhibited a significant increase in MMP-2 protein expression ( $\mathrm{p}<0.01$; Fig. 8). This AMI-induced increase in MMP-2 protein expression was reversed by treatment with osthole ( $\mathrm{p}<0.01 ;$ Fig. 8 ).

Effects of osthole on the phosphorylation of MAPK (JNK, p38 MAPK and ERK1/2) proteins. In order to further explore the cardioprotective mechanisms of action of osthole, the phosphorylation levels of JNK, p38 MAPK and ERK1/2 (p-JNK, p-p38 and p-ERK1/2) were examined by western blot analysis. We found that compared with the sham-operated group, the rats with AMI (vehicle-treated group) exhibited an increase in $\mathrm{p}-\mathrm{JNK}$ and $\mathrm{p}-\mathrm{p} 38$ protein expression $(\mathrm{p}<0.01)$, in comparison with the sham-operated group (Fig. 9A-C); however, treatment with osthole reduced p-JNK and p-p38 expression in a dose-dependant manner. We noted that p-ERK1/2 protein expression in the vehicle-treated group was effectively suppressed, compared to the sham-operated group (Fig. 9A and D). However, treatment with osthole (1, 3 and $10 \mathrm{mg} / \mathrm{kg}$ ) significanlty increased $\mathrm{p}$-ERK1/2 epxression $(\mathrm{p}<0.01)$ compared to the vehicle-treated group. As expected, pre-treatment with osthole reversed the effects of AMI on MAPK signaling pathways in the rats with AMI rats.

Effects of osthole on caspase-3 and caspase-9 activities. The apoptotic pathway was also examined in the present study. We observed a significant increase in caspase- 3 and caspase- 9 activities in the rats with AMI $(\mathrm{p}<0.01)$ compared to the sham-operated group (Fig. 10). However, these effects were significantly reversed by treatment with osthole.

\section{Discussion}

In patients with AMI, the reduction of myocardial cell viability and ventricular remodeling are the main factors responsible for heart failure and even death in the long-term (17). With the widespread application of emergency thrombolysis, emergency interventional therapy and coronary bypass surgery, 
A

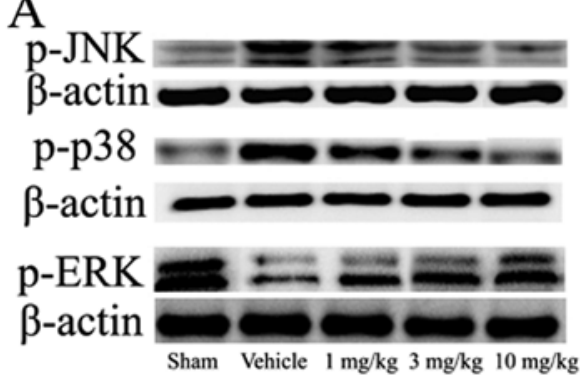

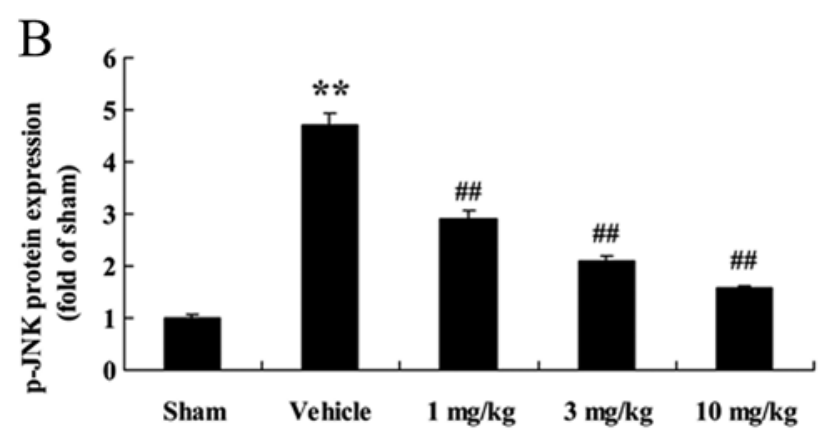

D

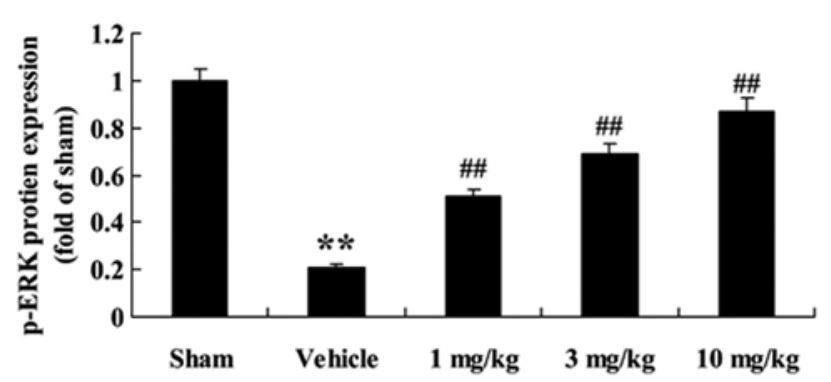

Figure 9. Effects of osthole on phosphorylation of mitogen-activated protein kinase (MAPK) [c-Jun N-terminal kinase (JNK), p38 MAPK and extracellular signal-regulated kinase 1/2 (ERK1/2)] protein expression levels (A) using western blot analysis and (B-D) statistical analysis of(B) p-JNK, (C) p-p38 and (D) p-ERK1/2 protein expression. ${ }^{* *} \mathrm{p}<0.01$ vs. sham-operated (sham) group; ${ }^{\# \#} \mathrm{p}<0.01$ vs. vehicle-treated (vehicle) group. Rats were treated with 1,3 and $10 \mathrm{mg} /$ $\mathrm{kg}$ of osthole.
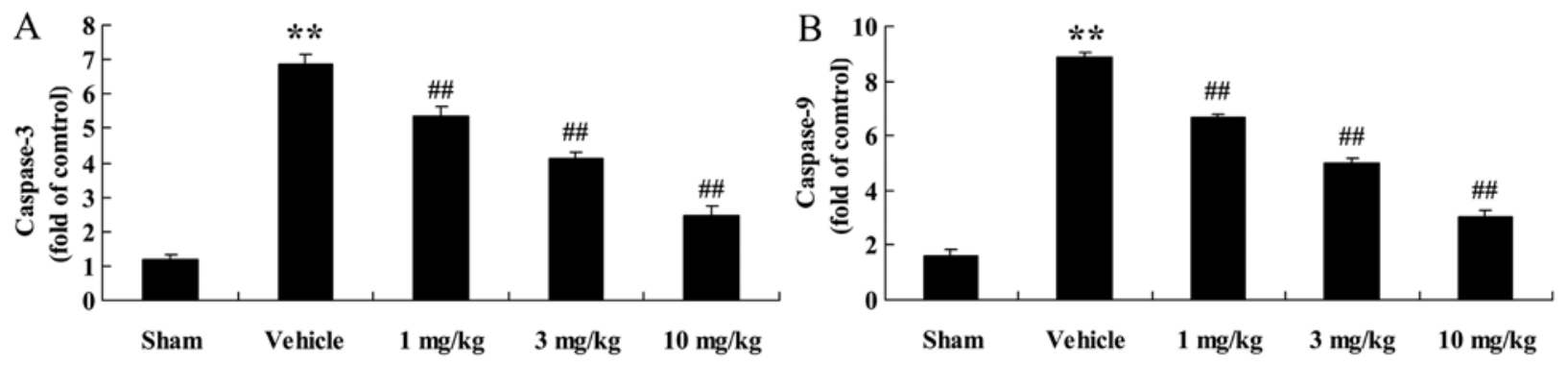

Figure 10. Effects of osthole on (A) caspase-3 and (B) caspase-9 activities. ${ }^{* *}$ p $<0.01$ vs. sham-operated (sham) group; ${ }^{\# \#}$ p $<0.01$ vs. vehicle-treated (vehicle) group. Rats were treated with 1,3 and $10 \mathrm{mg} / \mathrm{kg}$ of osthole.

the mortality rate of patients suffering from AMI has been greatly reduced and the number of survivors has increased significantly (18). In this study, we found that treatment with osthole markedly reduced the levels of CK, CK-MB, LDH and cTnT in the serum of rats with AMI. In particular, Wei et al reported that osthole was capable of reducing hyperalgesia due to lumbar disc herniation (19). In the present study, the infarct size of rats with AMI was significantly reduced following treatment with osthole; however, the exact mechanisms involved require further investigation. This reduction in the infarct size, however, indicates that osthole exerts protective effects on heart tissue and may protect against AMI (as shown in our rat model).

TLRs are an integral component of the inflammation process. TLR 2 and TLR4 are the most common and most well characterized as regards inflammatory responses in AMI. They are expressed predominantly in monocytes/macrophages and neutrophils. TLR2 is involved in the recognition of inflammatory reactions in AMI and plays an important role in the immune system. The peptidoglycan subunits are recognized by the NOD family proteins, in particular by NOD1 and NOD 2. NOD1 and NOD2 are involved primarily in mediating antibacterial and anti-inflammatory defenses. They are intracellular proteins involved in innate immunity and are associated with chronic inflammatory diseases in humans. In the present study, we demonstrated that there was a marked increase in TLR2, TLR4 and NOD2 gene expression in the rats with AMI compared to the sham-operated rats, and this effect was suppressed in a dose-dependent manner by treatment with osthole, implying that the cardioprotective effects of osthole are achieved through mediating TLR2/4 and NOD1/2 expression.

Previous research has demonstrated that NO exerts a cardioprotective effect against AMI. The effects of NO on myocardial infarction are associated with both its proand anti-apoptotic properties depending on the source of 
NO (20). NO is generated from the guanidinium group of L-arginine in an NADPH-dependent reaction catalyzed by NO synthase (NOS). At present, there are three known isoforms of NOS, including neuronal NOS (nNOS or NOS1), inducible NOS (iNOS or NOS2) and endothelial cell NOS (eNOS or NOS3). Of these isoforms, eNOS is not only expressed in the endocardium and endothelium of the coronary vasculature, but is also found in cardiac myocytes and in specialized cardiac conduction systems, such as sinoatrial and atrioventricular nodal tissues (21). It is widely accepted that NO produced from eNOS in the heart plays a critical role in coronary vasodilation and the inhibition of mitochondrial $\mathrm{O}_{2}$ consumption. A previous study indicated that myocardial injury was exacerbated in $\mathrm{eNOS}^{-/-}$mice following ischemic insults, suggesting a protective effect of eNOS-derived NO (22). In the present study, we found that osthole significantly and dose-dependently promoted the activation of eNOS and decreased COX-2 expression in rats with AMI. A previous study also demonstrated that osthole relaxed the pulmonary arteries via the Akt-eNOS-NO signaling pathway in rats (23). Yang et al also reported that osthole attenuated focal segmental glomerulosclerosis by inhibiting NF- $\kappa \mathrm{B}-$ mediated COX-2 expression (24).

TNF- $\alpha$, IL- $1 \beta$ and IL- 6 are closely related to disease severity and the prognosis of patients (25). In a previous study, it has been verified that, in atherosclerosis, TNF- $\alpha$, IL-1, IL-8 and other inflammatory factors are activated through $\mathrm{NF}-\kappa \mathrm{B}$. It was verified that activated $\mathrm{NF}-\kappa \mathrm{B}$ exists in smooth muscle cells, macrophages and endothelial cells in atherosclerosis (26). Therefore, it is clear that activated $N F-\kappa B$ participates in the process of ventricular remodeling. In the present study, we demonstrated that osthole reduced the activities of $\mathrm{NF}-\kappa \mathrm{B}$, TNF- $\alpha$, IL-1 $\beta$ and IL- 6 in AMI rats. A previous study found that osthole ameliorated renal ischemia-reperfusion injury by restraining the inflammatory response (27). In another previous study, osthole was also reported to weaken the inflammatory reaction following permanent middle cerebral artery occlusion in rats (28).

MMPs are secreted by myocardial cells, vascular endothelial cells, smooth muscle cells, foam cells and other cells, including the protease family that depends on $\mathrm{Ca}^{2+}$ and $\mathrm{Zn}^{2+}$. It has been demonstrated that MMPs are proteases which adjust and control the ECM, and they can promote the degradation of the ECM, accelerate the development of atheromatous plaque and lead to the formation of unstable plaque $(29,30)$. Prior research has indicated that MMP-2 reflects the status of atherosclerotic plaque, which plays an important role in a series of processes of occurrences and the development of AMI (31). In the present study, we demonstrated that treatment with osthole decreased the expression of MMP-2. Similarly, osthole was previously found to reduce the levels of MMP-2 and MMP-9 in the A549 human lung cancer cells (32). Moreover, Yang et al reported that osthole effectively inhibited the MMP-2 promoter in breast cancer cells (33).

Emerging evidence implies that MAPK signaling cascades are involved in cardiac myocyte apoptosis. The MAPK family contains three major subgroups, namely ERK, JNK and p38 MAPK. These are activated in response to myocardial infarction. It is generally believed that the inhibition of the ERK pathway enhances ischemia/reoxygen- ation-induced apoptosis in cultured cardiac myocytes and exacerbates myocardial injury in isolated rat hearts following ischemia-reperfusion (7). Liu et al (34) also reported that the phosphorylation of ERK was decreased in a rat model of AMI, and that treatment with baicalin potently suppressed this reduction. The present study demonstrated a marked decrease in p-ERK levels in rats with AMI, which is consistent with the results of previous studies (34) and, more importantly, there was an evident increase in the phosphorylated levels of ERK following treatment with osthole. This implies that the activation of the ERK cascade should be regarded as a critical signaling pathway for the cardoioprotective effect of osthole in rats with AMI. By contrast, it has been demonstrated that the activation of JNK and p38 MAPK exerts deleterious effects on post-ischemic myocardial apoptosis and cardiac function recovery (35). It was previously found that the inhibition of JNK1 markedly suppressed reoxygenation-induced apoptosis in rat cardiac myocytes (36). However, the activation of JNK by transfection with MKK7 in cardiomyocytes, an upstream activator of JNK, has been shown to induce myocardial hypertrophy, but not apoptosis (9). In terms of p38 MAPK, the inhibition of the cardiac p38 MAPK pathway by SB203580, a specific inhibitor, was shown to delay ischemic cell death in the pig myocardium (37). In line with these findings, our data demonstrated a marked elevation in p-JNK (the activated form of JNK) and p-p38 (the activated form of p38) in rats with AMI. Furthermore, treatment with osthole significantly diminished the expression of p-JNK and p-p38 in the rats with AMI. Taken together, the activation of ERK and the suppression of JNK, as well as p38 signaling pathways are conceived of as one of the most important cardioprotective mechanisms of osthole against myocardial infarction-induced cardiomyocyte apoptosis in rats.

Myocardial infarction often occurs when the myocardial blood supply is interrupted suddenly or persistently, and this contributes to marked cardiomyocyte apoptosis. Caspases are evolutionarily conserved cysteinyl proteases which play a pivotal role in the initiation and execution of cellular apoptosis (38); caspase-3 serves as an executioner molecule and is the most abundant caspase under normal and pathological conditions. A previous study illustrated that caspase-3 activated caspase-activated DNase, and this eventually led to DNA fragmentation and cell loss (39). In addition, a marked elevation in caspase- 3 has been observed in Wistar rats with isoproterenol-induced AMI (40). The results from our current study revealed that the levels of caspase- 3 in the infarcted rat hearts were altered and that treatment with osthole downregulated caspase- 3 in the rats with AMI. It is plausible that the beneficial effects of osthole are associated with its regulation of caspase-3, finally exerting anti-apoptotic effects on infarcted rat hearts. Of note, treatment with osthole reduced caspase- 3 and caspase- 9 activities, which implies that osthole protects myocardial cells and decreases cellular apoptosis. In a previous study, it was demonstrated that osthole significantly reduced the activity of caspase- 3 in PC12 cells (41). Ding et al emphasized that osthole inhibited the proliferation of human osteosarcoma cells through the expression of Bcl-2, Bax and caspase-3 (42). Zheng et al also illustrated that osthole ameliorated renal ischemia-reperfusion injury in rats by decreasing caspase- 3 activity (43). 
In conclusion, this study demonstrated the cardioprotective effects of osthole, and that its cardioprotective effects may be associated with the inhibition of inflammatory reactons, the decrease in MMP-2 expression and the activation of p-ERK. These findings suggest that osthole has the potential to be used as a drug for the treatment of AMI.

\section{References}

1. Bradshaw PJ, Trafalski S, Hung J, Briffa TG and Einarsdóttir K Outcomes after first percutaneous coronary intervention for acute myocardial infarction according to patient funding source. BMC Health Serv Res 14: 405, 2014.

2. Go AS, Mozaffarian D, Roger VL, Benjamin EJ, Berry JD, Blaha MJ, Dai S, Ford ES, Fox CS, Franco S, et al: Heart disease and stroke statistics - 2014 update: a report from the American Heart Association. Circulation 129: e28-e292, 2014.

3. Wollenweber T, Roentgen P, Schäfer A, Schatka I, Zwadlo C, Brunkhorst $T$, Berding $G$, Bauersachs $J$ and Bengel FM: Characterizing the inflammatory tissue response to acute myocardial infarction by clinical multimodality noninvasive imaging. Circ Cardiovasc Imaging 7: 811-818, 2014.

4. Könnecke $\mathrm{H}$ and Bechmann I: The role of microglia and matrix metalloproteinases involvement in neuroinflammation and gliomas. Clin Dev Immunol 2013: 914104, 2013.

5. Squire IB, Evans J, Ng LL, Loftus IM and Thompson MM: Plasma MMP-9 and MMP-2 following acute myocardial infarction in man: correlation with echocardiographic and neurohumoral parameters of left ventricular dysfunction. J Card Fail 10: 328-333, 2004.

6. Schaeffer HJ and Weber MJ: Mitogen-activated protein kinases: specific messages from ubiquitous messengers. Mol Cell Biol 19: 2435-2444, 1999.

7. Yue TL, Wang C, Gu JL, Ma XL, Kumar S, Lee JC, Feuerstein GZ, Thomas H, Maleeff B and Ohlstein EH: Inhibition of extracellular signal-regulated kinase enhances Ischemia/Reoxygenation-induced apoptosis in cultured cardiac myocytes and exaggerates reperfusion injury in isolated perfused heart. Circ Res 86: 692-699, 2000.

8. Aikawa R, Komuro I, Yamazaki T, Zou Y, Kudoh S, Tanaka M, Shiojima I, Hiroi Y and Yazaki Y: Oxidative stress activates extracellular signal-regulated kinases through $\mathrm{Src}$ and Ras in cultured cardiac myocytes of neonatal rats. J Clin Invest 100: 1813-1821, 1997

9. Wang Y, Su B, Sah VP, Brown JH, Han J and Chien KR: Cardiac hypertrophy induced by mitogen-activated protein kinase kinase 7, a specific activator for c-Jun NH2-terminal kinase in ventricular muscle cells. J Biol Chem 273: 5423-5426, 1998.

10. Mackay K and Mochly-Rosen D: An inhibitor of p38 mitogenactivated protein kinase protects neonatal cardiac myocytes from ischemia. J Biol Chem 274: 6272-6279, 1999.

11. Nam HH, Jun DW, Jeon HJ, Lee JS, Saeed WK and Kim EK: Osthol attenuates hepatic steatosis via decreased triglyceride synthesis not by insulin resistance. World J Gastroenterol 20: $11753-11761,2014$.

12. Chen R, Xue J and Xie M: Osthole regulates TGF- $\beta 1$ and MMP-2/9 expressions via activation of PPAR $\alpha / \gamma$ in cultured mouse cardiac fibroblasts stimulated with angiotensin II. J Pharm Pharm Sci 16: 732-741, 2013.

13. Yu HP, Liu FC, Tsai YF and Hwang TL: Osthole attenuates hepatic injury in a rodent model of trauma-hemorrhage. PLoS One 8: e65916, 2013.

14. Wang XY, Dong WP, Bi SH, Pan ZG, Yu H, Wang XW, Ma T, Wang $J$ and Zhang WD: Protective effects of osthole against myocardial ischemia/reperfusion injury in rats. Int J Mol Med 32: 365-372, 2013.

15. Hoda MN, Li W, Ahmad A, Ogbi S, Zemskova MA, Johnson MH, Ergul A, Hill WD, Hess DC and Sazonova IY: Sex-independent neuroprotection with minocycline after experimental thromboembolic stroke. Exp Transl Stroke Med 3: 16, 2011.

16. Hoda MN, Siddiqui S, Herberg S, Periyasamy-Thandavan S, Bhatia K, Hafez SS, Johnson MH, Hill WD, Ergul A, Fagan SC, et al: Remote ischemic perconditioning is effective alone and in combination with intravenous tissue-type plasminogen activator in murine model of embolic stroke. Stroke 43: 2794-2799, 2012.
17. Kilickesmez KO, Bingöl G, Bulut L, Sinan UY, Abaci O, Ersanli $\mathrm{M}$ and Gurmen T: Relationship between serum endothelin-1 level and spontaneous reperfusion in patients with acute myocardial infarction. Coron Artery Dis 26: 37-41, 2015.

18. Dziewierz A, Rakowski T and Dudek D: Abciximab in the management of acute myocardial infarction with ST-segment elevation: evidence-based treatment, current clinical use, and future perspectives. Ther Clin Risk Manag 10: 567-576, 2014.

19. Wei M, Mo SL, Nabar NR, Chen Y, Zhang JJ, He QL, Zou XN Liu XG, Sun LB and Zhou SF: Modification of rat model of sciatica induced by lumber disc herniation and the antiinflammatory effect of osthole given by epidural catheterization. Pharmacology 90: 251-263, 2012.

20. Yang G, Fang Z, Liu Y, Zhang H, Shi X, Ji Q, Lin Q and Lin R: Protective effects of Chinese traditional medicine buyang huanwu decoction on myocardial injury. Evid Based Complement Alternat Med 2011: 930324, 2011.

21. Balligand JL and Cannon PJ: Nitric oxide synthases and cardiac muscle. Autocrine and paracrine influences. Arterioscler Thromb Vasc Biol 17: 1846-1858, 1997.

22. Sumeray MS, Rees DD and Yellon DM: Infarct size and nitric oxide synthase in murine myocardium. J Mol Cell Cardiol 32: 35-42, 2000.

23. Yao L, Lu P, Li Y, Yang L, Feng H, Huang Y, Zhang D, Chen J and Zhu D: Osthole relaxes pulmonary arteries through endothelial phosphatidylinositol 3-kinase/Akt-eNOS-NO signaling pathway in rats. Eur J Pharmacol 699: 23-32, 2013.

24. Yang SM, Chan YL, Hua KF, Chang JM, Chen HL, Tsai YJ, Hsu YJ, Chao LK, Feng-Ling Y, Tsai YL, et al: Osthole improves an accelerated focal segmental glomerulosclerosis model in the early stage by activating the Nrf2 antioxidant pathway and subsequently inhibiting NF- $\mathrm{BB}$-mediated COX-2 expression and apoptosis. Free Radic Biol Med 73: 260-269, 2014.

25. Stein A, Mohr F, Laux M, Thieme S, Lorenz B, Cetindis M, Hackl J, Groha P, Demetz G, Schulz S, et al: Erythropoietininduced progenitor cell mobilisation in patients with acute ST-segment-elevation myocardial infarction and restenosis. Thromb Haemost 107: 769-774, 2012.

26. Turner NA, Das A, Warburton P, O'Regan DJ, Ball SG and Porter KE: Interleukin-1alpha stimulates proinflammatory cytokine expression in human cardiac myofibroblasts. Am J Physiol Heart Circ Physiol 297: H1117-H1127, 2009.

27. Zheng Y, Lu M, Ma L, Zhang S, Qiu M and Ma X: Osthole ameliorates renal ischemia-reperfusion injury by inhibiting inflammatory response. Urol Int 91: 350-356, 2013.

28. Chao X, Zhou J, Chen T, Liu W, Dong W, Qu Y, Jiang X, Ji X, Zhen $\mathrm{H}$ and Fei Z: Neuroprotective effect of osthole against acute ischemic stroke on middle cerebral ischemia occlusion in rats. Brain Res 1363: 206-211, 2010.

29. Wang KF, Huang PH, Chiang CH, Hsu CY, Leu HB, Chen JW and Lin SJ: Usefulness of plasma matrix metalloproteinase-9 level in predicting future coronary revascularization in patients after acute myocardial infarction. Coron Artery Dis 24: 23-28, 2013.

30. Periasamy S, Mo FE, Chen SY, Chang CC and Liu MY: Sesamol attenuates isoproterenol-induced acute myocardial infarction via inhibition of matrix metalloproteinase-2 and -9 expression in rats. Cell Physiol Biochem 27: 273-280, 2011.

31. Dai F, Xiao GL and Pan J: Correlation between serum MMP-2 and MMP-9 in patients with acute myocardial infarction before and after PCI. Xi Bao Yu Fen Zi Mian Yi Xue Za Zhi 25: 716-718, 2009 (In Chinese).

32. Xu XM, Zhang Y, Qu D, Feng XW, Chen Y and Zhao L: Osthole suppresses migration and invasion of A549 human lung cancer cells through inhibition of matrix metalloproteinase- 2 and matrix metallopeptidase-9 in vitro. Mol Med Rep 6: 1018-1022, 2012.

33. Yang D, Gu T, Wang T, Tang Q and Ma C: Effects of osthole on migration and invasion in breast cancer cells. Biosci Biotechnol Biochem 74: 1430-1434, 2010.

34. Liu X, Gu J, Fan Y, Shi H and Jiang M: Baicalin attenuates acute myocardial infarction of rats via mediating the mitogen-activated protein kinase pathway. Biol Pharm Bull 36: 988-994, 2013.

35. Shimada K, Nakamura M, Ishida E, Kishi $M$ and Konishi N: Roles of p38- and c-jun NH2-terminal kinase-mediated pathways in 2-methoxyestradiol-induced p53 induction and apoptosis. Carcinogenesis 24: 1067-1075, 2003.

36. Hreniuk D, Garay M, Gaarde W, Monia BP, McKay RA and Cioffi CL: Inhibition of c-Jun N-terminal kinase 1, but not c-Jun N-terminal kinase 2, suppresses apoptosis induced by ischemia/reoxygenation in rat cardiac myocytes. Mol Pharmacol 59: 867-874, 2001. 
37. Barancik M, Htun P, Strohm C, Kilian S and Schaper W: Inhibition of the cardiac p38-MAPK pathway by SB203580 delays ischemic cell death. J Cardiovasc Pharmacol 35: 474-483, 2000.

38. Wang W, Xu J, Li L, Wang P, Ji X, Ai H, Zhang L and Li L: Neuroprotective effect of morroniside on focal cerebral ischemia in rats. Brain Res Bull 83: 196-201, 2010.

39. Tanaka M, Mokhtari GK, Terry RD, Balsam LB, Lee KH, Kofidis T, Tsao PS and Robbins RC: Overexpression of human copper/zinc superoxide dismutase (SOD1) suppresses ischemiareperfusion injury and subsequent development of graft coronary artery disease in murine cardiac grafts. Circulation 110 (Suppl 1): II200-II206, 2004.

40. Guo J, Li HZ, Wang LC, Zhang WH, Li GW, Xing WJ, Wang R and $\mathrm{Xu} C \mathrm{CQ}$ : Increased expression of calcium-sensing receptors in atherosclerosis confers hypersensitivity to acute myocardial infarction in rats. Mol Cell Biochem 366: 345-354, 2012.
41. Shokoohinia Y, Hosseinzadeh L, Moieni-Arya M, Mostafaie A and Mohammadi-Motlagh HR: Osthole attenuates doxorubicin-induced apoptosis in PC12 cells through inhibition of mitochondrial dysfunction and ROS production. BioMed Res Int 2014: 156848, 2014.

42. Ding Y, Lu X, Hu X, Ma J and Ding H: Osthole inhibits proliferation and induces apoptosis in human osteosarcoma cells. Int $\mathbf{J}$ Clin Pharmacol Ther 52: 112-117, 2014.

43. Zheng Y, Lu M, Ma L, Zhang S, Qiu M and Wang Y: Osthole ameliorates renal ischemia-reperfusion injury in rats. J Surg Res 183: 347-354, 2013. 